\title{
The Dewey monitor: Pulse oximetry can independently detect hypoxia in a rebreather diver
}

\author{
Rachel M. Lance, PhD 1,2, Michael J. Natoli, MS ${ }^{3}$, Sophia A.S. Dunworth, BS ${ }^{4}$, \\ John J. Freiberger, MD 3,5, Richard E. Moon, MD 3,5,6 \\ ${ }^{1}$ Duke University, Department of Biomedical Engineering, Durham, N.C. U.S. \\ 2 Naval Surface Warfare Center Panama City Division (NSWC PCD), Code E15 Underwater Systems \\ Development and Acquisition, Panama City, Fla. U.S. \\ ${ }^{3}$ Duke University Medical Center, Center for Hyperbaric Medicine and Environmental Physiology, \\ Durham, N.C. U.S. \\ 4 Duke University School of Medicine, Durham, N.C. U.S. \\ ${ }^{5}$ Duke University Medical Center, Department of Anesthesiology, Durham, N.C. U.S. \\ ${ }^{6}$ Duke University Medical Center, Department of Medicine, Durham, N.C. U.S. \\ CORRESPONDING AUTHOR: Rachel Lance-aquaticrachel@gmail.com
}

\section{ABSTRACT}

Rebreather diving has one of the highest fatality rates per man hour of any diving activity in the world. The leading cause of death is hypoxia, typically from equipment or procedural failures. Hypoxia causes very few symptoms prior to causing loss of consciousness. Additionally, since the electronics responsible for controlling oxygen levels in rebreathers often control their alarm systems, frequently divers do not receive any external warnings.

This study investigated the use of a forehead pulse oximeter as an independent warning device in the event of rebreather failure. Ten test subjects (seven male, three female, median age 29, range 26-35) exercised at a targeted rate of $2 \mathrm{~L} /$ minute oxygen consumption while on a non-functional rebreather breathing loop (mean consumption achieved $2.09 \pm 0.36 \mathrm{~L} /$ minute).

Each subject was tested both at the surface and at pressurized depth of $77 \mathrm{fsw}$ (starting $\mathrm{pO}_{2}=0.7 \mathrm{~atm}$ ). The data show that a pulse oximeter could be used to provide an Mk 16 rebreather diver with a minimum mean of 49 seconds ( \pm 17 seconds SD) of warning time after a noticeable change in blood oxygen saturation $\left(\mathrm{SpO}_{2} \leq 95 \%\right)$ but before any risk of loss of consciousness (calculated $\mathrm{SpO}_{2} \leq 80 \%$ ), so that the diver may take mitigating actions. No statistical difference in warning time was found between the tests at surface and at $77 \mathrm{fsw}(\mathrm{P}=0.46)$.

\section{INTRODUCTION}

Rebreathers are a form of underwater diving equipment that recycle the diver's breathing gas by removing carbon dioxide and injecting oxygen to maintain a desired mixture of inspired gases. Mixed-gas rebreathers have been steadily increasing in popularity in both the military and civilian diving communities over the past several decades. With this increase in popularity has come a number of rebreather-related diving fatalities. It is often difficult to ascertain the exact cause of diving fatalities because they occur in an underwater environment and therefore are confounded by additional complications like water in the decedent's lungs.
However, the most frequent confirmed cause of death on rebreathers is hypoxia, with almost double the fatalities of the next most prevalent cause, hypercapnia [1]. According to information collected through 2016 by the Open Revolution Safety Initiative, 229 civilian rebreather fatalities with known causes were recorded. Of these, $38.9 \%$ were the result of hypoxia; in contrast, only $9.6 \%$ were due to hyperoxia $[1,2]$.

The goal of this study was to evaluate the use of a pulse oximeter as a means for detecting hypoxia, completely separately from the rebreather electronics. Ideally, this oximeter could be used as an independent monitor and redundant alarm system to alert the diver

KEYWORDS: hypoxia; rebreather; electronics failure; pulse oximeter; diver 


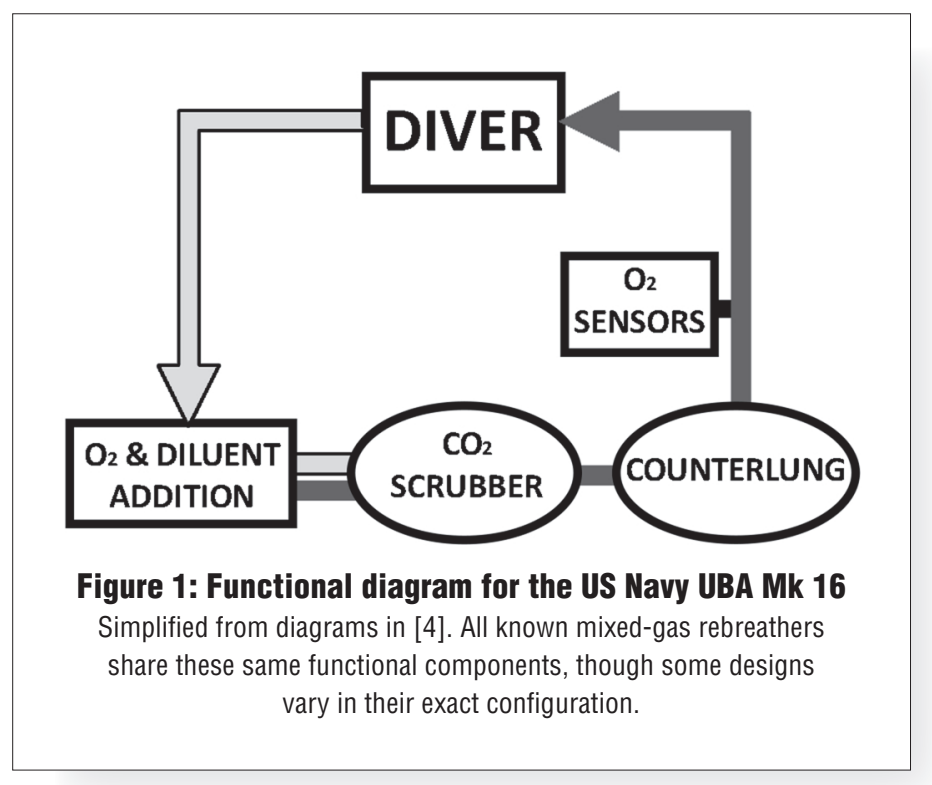

of hypoxia before any risk of loss of consciousness. We hypothesized that during moderate exercise a pulse oximeter could provide a minimum of 10 seconds of useful warning time before the breathing loop reached oxygen levels at which loss of consciousness might occur. Diluent and oxygen addition valves on most rebreather models are intentionally located within easy reach of the diver (e.g., on the outside lower portion of the rebreather), so divers require only a few seconds' warning to be able to either bail out to an open-circuit gas supply or, failing that, to add gas manually and maintain a survivable level of oxygen in the breathing loop.

\section{BACKGROUND}

Mixed-gas rebreathers are designed to simultaneously reduce the amount of gas a diver must carry while lengthening the amount of time they can stay underwater. The devices accomplish these seemingly contradictory goals by processing and recycling the diver's breathing gas. First, the diver exhales into a unidirectional valve, which leads to a counterlung and carbon dioxide $\left(\mathrm{CO}_{2}\right)$ scrubber. The scrubber is filled with a granular material that removes the carbon dioxide from the expired gas via a chemical reaction. The counterlung is a flexible bag that stores the volume of the expired gas temporarily while the diver is in the exhalation phase of each breathing cycle. As the diver inhales, the gas is then pulled from the scrubber and counterlung through another unidirectional valve and returned to the diver via the mouthpiece. The level of oxygen is detected by oxygen sensors located within the breathing loop.

Owing to frequent failure of $\mathrm{O}_{2}$ sensors, the great majority of rebreather designs use three sensors whose output signals are combined using voting logic [3]. The oxygen partial pressure detected by the sensors is then used to determine when a solenoid should inject more oxygen into the breathing loop. Alternatively, some designs rely upon the diver to manually inject oxygen as needed. The breathing loop is also connected to a supply of diluent gas that is automatically injected to compensate for volumetric compression during descent.

Several commercial companies manufacture mixedgas rebreathers. While there is some variation in the physical configuration and order of these components between designs, all known mixed-gas rebreather designs use these same fundamental principles. A diagram describing the function of the U.S. Navy's Underwater Breathing Apparatus (UBA) Mk 16 (referred to as Mk 16) is shown as Figure 1.

One reason hypoxia causes many fatalities is because all known mixed-gas rebreather designs have at least one single point of failure that can lead to hypoxia. Specifically, the electronics that control both the level of oxygen in the breathing loop and the alarm systems that warn a diver of low oxygen levels are linked by one failure point, such as the use of one computer or a single set of oxygen sensors. Indeed, preventable fatalities have occurred because the unit was simply 


\section{UHM 2017,VOL. 44, NO. 6 - PULSE OXIMETRY TO DETECT REBREATHER HYPOXIA}

not turned on before the dive, precluding either the injection system or the alarms from working $[1,2]$. Other hypoxia fatalities have occurred because external factors have impaired the function of the rebreather ]5].

Many divers argue that hypoxia has recognizable signs and symptoms. However, studies by the U.S. Air Force have concluded that personnel are unlikely to recognize these signs and symptoms without adequate prior training. One of the first signs of hypoxia is mental confusion, which means that often a diver would not be able to recognize hypoxia because of the hypoxia itself. The Air Force studied pilots' abilities to recognize hypoxia before loss of consciousness (LOC), and found that $94 \%$ of the pilots who had not undergone hypobaric chamber training failed to recognize the symptoms and experienced LOC in-flight, even though they had been briefed on what symptoms to expect [6]. Therefore, if a diver is involved in a low-oxygen situation, it is highly likely that the diver will lose consciousness underwater.

Pulse oximetry is a robust technology with decades of documented use in clinical settings [7]. Oximetry has been used to study bradycardia and apnea in freedivers (e.g., refs. $[8,9]$ ), but we are unaware of any studies using oximetry in conjunction with closedcircuit rebreathers. It should be noted that pulse oximetry measures the blood oxygen saturation only at the site where the oximeter is located. Thus, when a person is cold and extremity blood flow is reduced, if the sensor is conventionally located on a fingertip there can be a marked delay in detection of hypoxemia [10].

\section{METHODS}

All testing was conducted with the approval of the Duke University Medical Center's Institutional Review Board (IRB). Test subjects were compensated volunteers who had given written informed consent. Each test subject was first evaluated using prescreening that determined their maximum oxygen consumption level $\left(\mathrm{VO}_{2} \max \right)$ and fitness to dive. Test subjects qualified for the study if they could achieve a $\mathrm{VO}_{2}$ max of $35 \mathrm{~mL} / \mathrm{kg} /$ minute for males or $30 \mathrm{~mL} / \mathrm{kg} /$ minute for females, were in the age range 18-40, were deemed medically fit to dive, and were neither smokers nor pregnant.

The "rebreather" used for this study was not a fully functional rebreather, but rather comprised only the breathing loop components of a U.S. Navy UBA Mk 16
[4]. Specifically, the mouthpiece, unidirectional valves, breathing hoses, counterlung, and carbon dioxide scrubber were used. No oxygen sensors were in place and no electronics were present, so it could not be considered a functional diving unit. The loop components were assembled for each test per official Navy protocol, including the use of Sofnolime 797 grade 8-12 mesh in the $\mathrm{CO}_{2}$ scrubber (Molecular Products, Boulder, $\mathrm{CO}$ ).

The breathing loop volume was determined to be $11 \mathrm{~L}$. The device as configured represented an accurate simulation of the work of breathing and loop volume of a functional Mk 16 in which the $\mathrm{O}_{2}$ sensors or addition system had failed. The inspired gas breathing hose was instrumented with a port that provided a continuous sample of the breathing gas to a precalibrated mass spectrometer (Perkin Elmer [refurbished by MA Tech Services], model MGA 1100). The mass spectrometer was calibrated both before and after testing using multiple calibration gas compositions and examining the response data for appropriate step increases and plateaus at equilibrium. The volume lost to sampling was determined to be negligible in comparison to the total loop volume.

During the experiment, subjects were instrumented with a forehead pulse oximeter (Nonin model 7500, Nonin Medical, Inc., Plymouth, Minnesota), a finger pulse oximeter (Nellcor model N200, Medtronic, Minneapolis, Minnesota), and a 3-lead EKG. All testing took place inside a dry hyperbaric chamber. Subjects were wearing a harness connected to the ceiling of the chamber as a safety precaution in case of loss of consciousness. They were instructed to maintain 75 RPMs on a bicycle ergometer with the pedal resistance set to target an oxygen consumption of $2 \mathrm{~L} /$ minute. Resistance levels were selected based on the results of each subject's $\mathrm{VO}_{2}$ max testing, which was also performed on cycle ergometers. A $2 \mathrm{~L} /$ minute consumption was selected as a moderate work rate with approximately the same relative intensity for all subjects given the level of fitness established by the $\mathrm{VO}_{2 \text { max }}$ screening criteria.

The subjects began the experiment with a mouthpiece (Hans Rudolph model 2700) providing them with air from a source external to the chamber to guarantee inspiratory gas composition. They exercised while on this mouthpiece for five minutes to achieve a steady state of oxygen consumption. During the last minute 
of exercise, each subject's exhaled gas was collected in a 200-L Douglas bag, and was later analyzed to determine rates of oxygen consumption and carbon dioxide production.

Mixed expired oxygen and carbon dioxide values from the collected gas were measured by mass spectrometry. Ventilation was determined from timing the bag collection and measuring the bag volume using a gas meter (model DTM 325-4, Elster American Meter Co., Nebraska City, Nebraska). After bag collection, the subjects were instructed to exhale fully and were handed the mouthpiece for the Mk 16 breathing loop. They then maintained their rate of exercise while breathing on the disabled breathing loop until oxygen levels fell sufficiently to meet either of two stop criteria: an inspired partial pressure of oxygen less than or equal to $0.12 \mathrm{~atm}\left(\mathrm{pO}_{2} \leq 0.12 \mathrm{~atm}\right)$, or blood oxygen saturation $\leq 80 \%$ on either pulse oximeter unit. A peripheral capillary oxygen saturation of $80 \%\left(\mathrm{SpO}_{2}=80 \%\right)$ was selected because it is higher than the steady-state value for subjects with a partial pressure of inspired oxygen of $0.12 \mathrm{~atm}\left(\mathrm{PiO}_{2}=0.12 \mathrm{~atm}\right)$. This is based on previous studies that measured the percentage of hemoglobin molecules in the arterial blood saturated with oxygen of $77.6 \pm 8.0 \%\left(\mathrm{SaO}_{2}=77.6 \pm 8.0 \%\right)$ (mean \pm $\mathrm{SD})$ at rest while at simulated altitude of 15,000 feet, equivalent to approximately $12 \%$ inspired oxygen [11, 12].

At an oxygen consumption of mean $\mathrm{VO}_{2}=2.3 \mathrm{~L} / \mathrm{min}$ ute under the same conditions, subjects measured $\mathrm{SaO}_{2}=65.4 \pm 2.5 \%$ with no negative incidents, indicating that a value of $80 \%$ would be safe for testing. The loop mouthpiece was then removed from the test subjects, who were instructed to stop exercise and breathe chamber air until blood oxygen saturation levels returned to normal, which typically required five to 10 seconds. This test was performed breathing air, first on the surface with the chamber door open (starting loop $\mathrm{pO}_{2}=0.21 \mathrm{~atm}$ ), then repeated at a depth of $77 \mathrm{fsw}$ (starting loop $\mathrm{pO}_{2}=0.7 \mathrm{~atm}$ ). Data were analyzed following completion of the study using Matlab R2013a (8.1.0.604, @TheMathWorks, Inc., Natick, Massachusetts) and JMP (v13.0.0, OSAS Institute Inc., Cary, North Carolina).

Falling oxygen partial pressures in a breathing loop were measured directly using mass spectrometry. The inspired gas times were offset by the measured delay times in the sample line to the mass spectrometer (6.2 seconds on the surface, 6.3 seconds at $77 \mathrm{fsw}$. Note: large delay times result from porting gas samples across the hyperbaric chamber walls). The partial pressure of oxygen $\left(\mathrm{pO}_{2}\right.$, atm) at any given time in the breathing loop is a function of the initial partial pressure of oxygen $\left(\mathrm{pO}_{2}\right.$ initial, atm), the duration of time that has passed $(t, \mathrm{~min})$, the rate of oxygen consumption by the diver $\left(\mathrm{VO}_{2}, \mathrm{~L} /\right.$ minute), and the total floodable volume of the breathing loop $\left(\mathrm{V}_{\text {total }}, \mathrm{L} / \mathrm{atm}\right)$. This relationship is shown as Equation (1) below.

$$
p \mathrm{O}_{2}=p \mathrm{O}_{2 \text { initial }}-t^{*} \frac{V \mathrm{O}_{2}}{V_{\text {total }}}
$$

Variation in the rate of oxyhemoglobin $\left(\mathrm{Hb}-\mathrm{O}_{2}\right)$ desaturation is most likely due to the variability among subjects in chemosensitivity. Those with a high hypoxic ventilatory response will hyperventilate to a greater degree and thus maintain a higher alveolar (and hence arterial) $\mathrm{pO}_{2}$ (see alveolar gas equation, provided as Equation (2), from reference [13]).

$$
\mathrm{PaO}_{2}=\mathrm{PiO}_{2}-\mathrm{PaCO}_{2}\left[\mathrm{FiO}_{2}+\frac{1-\mathrm{FiO}_{2}}{\mathrm{RER}}\right]
$$

The tests showed relatively little mathematical influence from variations in respiratory exchange ratio (RER) (mean=0.96, $\mathrm{SD}=0.1$ ) with regard to the calculations of the alveolar gas equation compared to the influence of changes in fraction of inspired oxygen $\left(\mathrm{FiO}_{2}\right)$. Thus, the variability in rates of $\mathrm{Hb}-\mathrm{O} 2$ desaturation must indicate variability in the arterial partial pressure of carbon dioxide $\left(\mathrm{PaCO}_{2}\right) \cdot \mathrm{PaCO}_{2}$ in turn may be reduced by a combination of the hypoxic and exercise ventilatory responses.

The length of the time between when the pulse oximeter registered a predetermined saturation percentage (typically 95\%) and either of the two experimental safety cutoffs $\left(\mathrm{SpO}_{2}=80 \%\right.$ on either oximeter OR $\left.\mathrm{pO}_{2}=0.12 \mathrm{~atm}\right)$ underestimates the actual length of warning time available to a diver. Prior studies have indicated that subjects can maintain consciousness indefinitely at a $\mathrm{pO}_{2}$ of 0.12 atm [14-16]; this value was chosen to incorporate additional conservatism into the safety cutoffs, and indeed in our experiments $\mathrm{pO}_{2}=0.12$ atm was attained well before the oxygen saturation values approached values where loss of consciousness might occur (defined conservatively as $\mathrm{SpO}_{2}<80 \%[11,12]$ (see Tables 1 and 2). 
Table 1: Numerical results and key values for tests on the surface

\begin{tabular}{|c|c|c|c|c|c|c|c|c|c|}
\hline test \# & age & $\mathrm{M} / \mathrm{F}$ & $\begin{array}{l}\text { weight } \\
\text { (kg) }\end{array}$ & $\begin{array}{l}\mathrm{O}_{2} \\
\text { consumption } \\
\text { (L.min-1 } \\
\text { STPD) }\end{array}$ & $\begin{array}{l}\mathrm{CO}_{2} \\
\text { production } \\
\text { (L.min-1 } \\
\text { STPD) }\end{array}$ & RER & $\begin{array}{l}\text { ending } \\
\mathrm{SpO}_{2} \\
(\%)\end{array}$ & $t^{\star}(s)$ & $\begin{array}{l}\text { warning } \\
\text { time (sec) } \\
(95 \%)\end{array}$ \\
\hline 1 & 35 & $\mathrm{M}$ & 81.4 & 1.816 & 2.332 & 1.28 & 85 & 363 & 32 \\
\hline 2 & 28 & $\mathrm{~F}$ & 63.6 & 1.505 & 1.473 & 0.98 & 89 & 439 & 30.5 \\
\hline 3 & 27 & $\mathrm{~F}$ & 62.7 & 1.685 & 1.712 & 1.02 & 87 & 392 & 33.4 \\
\hline 4 & 26 & $M$ & 93.3 & 2.068 & 2.033 & 0.98 & 94 & 319 & 55 \\
\hline 5 & 30 & $\mathrm{M}$ & 95.4 & \multicolumn{6}{|c|}{ [data point not used - mass spec. error during hypoxic period] } \\
\hline 6 & 28 & M & 85.5 & + & + & + & 93 & + & 39.7 \\
\hline 7 & 32 & M & 77.7 & 1.967 & 1.986 & 1.01 & 93 & 336 & 59.5 \\
\hline 8 & 27 & M & 77.5 & 2.405 & 2.430 & 1.01 & 94 & 274 & 35 \\
\hline 9 & 32 & $\mathrm{~F}$ & 55.8 & 1.546 & 1.565 & 1.01 & 90 & 427 & 39.1 \\
\hline 10 & 32 & $M$ & 97.5 & 2.145 & 2.012 & 0.94 & 86 & 308 & 46.3 \\
\hline MEAN & 29.8 & -- & 79.04 & 1.975 & 1.975 & 1.00 & 90.1 & 344 & 41.2 \\
\hline ST.DEV & 2.9 & -- & 14.6 & 0.335 & 0.335 & 0.13 & 3.6 & 68.3 & 10.3 \\
\hline
\end{tabular}

Warning time (95\%) is defined as the time from $\mathrm{SpO}_{2}=95 \%$ to the time calculated for $\mathrm{SpO}_{2}=80 \%$.

+ Indicates a mass spectrometer error during measurement of the collected exhaled gas only: $\mathrm{O}_{2}$ consumption and $\mathrm{CO}_{2}$ production rates were therefore not available and could not be used to calculate RER and $\mathrm{t}^{\star}$ values.

Table 2: Numerical results and key values for tests at 77 fsw

\begin{tabular}{|c|c|c|c|c|c|c|c|c|c|}
\hline test \# & age & $M / F$ & $\begin{array}{l}\text { weight } \\
\text { (kg) }\end{array}$ & $\begin{array}{l}\mathrm{O}_{2} \\
\text { consumption } \\
\text { (L.min }{ }^{-1} \\
\text { STPD) }\end{array}$ & $\begin{array}{l}\mathrm{CO}_{2} \\
\text { production } \\
\text { (L.min }{ }^{-1} \\
\text { STPD) }\end{array}$ & RER & $\begin{array}{l}\text { ending } \\
\mathrm{SpO}_{2} \\
(\%)\end{array}$ & $t^{*}(s)$ & $\begin{array}{l}\text { warning } \\
\text { time (sec) } \\
(95 \%)\end{array}$ \\
\hline 1 & 35 & M & 81.4 & \multicolumn{6}{|c|}{ [data point not used - mass spec. error during hypoxic period] } \\
\hline 2 & 28 & $\mathrm{~F}$ & 63.6 & 1.772 & 1.608 & 0.91 & 91 & 372 & 69.2 \\
\hline 3 & 27 & $\mathrm{~F}$ & 62.7 & 2.284 & 1.957 & 0.86 & 84 & 289 & 38.3 \\
\hline 4 & 26 & M & 93.3 & 2.395 & 2.301 & 0.96 & 95 & 276 & 86.8 \\
\hline 5 & 30 & $M$ & 95.4 & 2.011 & 2.189 & 1.09 & 93 & 328 & 56.9 \\
\hline 6 & 28 & $M$ & 85.5 & 2.347 & 2.026 & 0.86 & 91 & 281 & 42.4 \\
\hline 7 & 32 & $M$ & 77.7 & 2.407 & 2.033 & 0.84 & 89 & 274 & $83.4 \neq$ \\
\hline 8 & 27 & $M$ & 77.5 & 2.917 & 2.299 & 0.79 & 90 & 226 & 45 \\
\hline 9 & 32 & $\mathrm{~F}$ & 55.8 & 2.007 & 1.866 & 0.93 & 85 & 329 & 46.8 \\
\hline 10 & 32 & $M$ & 97.5 & 2.266 & 1.987 & 0.88 & 87 & 291 & 36.7 \\
\hline MEAN & 29.8 & -- & 79.04 & 2.035 & 2.035 & 0.92 & 89.4 & 301 & 56.2 \\
\hline ST.DEV & 2.9 & -- & 14.6 & 0.207 & 0.207 & 0.10 & 3.6 & 41.6 & 19.2 \\
\hline
\end{tabular}

Warning time (95\%) is defined as the time from $\mathrm{SpO}_{2}=95 \%$ to the time calculated for $\mathrm{SpO}_{2}=80 \%$.

$\neq$ This test would have provided the only false alarm at the $95 \%$ cutoff level. 
Therefore, to calculate a more physiologically relevant warning time, the $\mathrm{SpO}_{2}$ levels for the last $15 \mathrm{sec}$ onds of each individual test (before the safety cutoffs) were separately fit with lines via least squares method. These lines were extrapolated until they were projected to reach $\mathrm{SpO}_{2}=80 \%$ to provide the calculated time at which each trial would have reached $80 \%$ saturation. While blood oxygen saturation shows a sigmoidal response curve over the full range (0-100\%) of saturation values, the section of the sigmoid between $80 \%-95 \%$ is sufficiently linear to justify this approximation. More specifically, a line that is fit to the Kelman equations [17] of the sigmoid using the slope between 95\% and $89.4 \%$ (the mean saturation at the time of experimental cutoff) provides an $\mathrm{R}^{2}=0.83$ fit with the sigmoid in the $80 \%-95 \%$ range of saturation values, and a mean of only $0.6 \%$ error. The "warning time" that the device could provide to a diver was defined as the time between the predetermined alarm level (typically $\mathrm{SpO}_{2}=95 \%$ ) and the time when the $\mathrm{SpO}_{2}$ was projected to reach $80 \%$. The data used were from the forehead oximeter because of the practical issues of building a warning device for diver use, including use of hands during working dives and circulatory delays in cold water [10]. The finger oximeter was used primarily as an additional safety measure and the resulting data were not used for analysis.

The warning times were analyzed using a two-way ANOVA with depth as a factor (JMP, v13.0.0, ${ }^{\circ}$ SAS Institute Inc., Cary, North Carolina) to compare the experimental alarm time (defined as the length of time between $\mathrm{SpO}_{2}=95 \%$ and the experimental safety cutoff $\mathrm{PiO}_{2}=0.12 \mathrm{~atm}$ ) with the independent variables of depth, rate of oxygen consumption, and $\mathrm{SpO}_{2}$ at the time the safety cutoff was reached. The purpose was to evaluate the variation in warning time as a function of the experimental parameters as well as the physiological parameter of blood oxygen saturation level. Gender and age were determined to be covariates of oxygen consumption and were therefore eliminated as variables. The relationship between the final $\mathrm{SpO}_{2}$ value and the experimental alarm time was then evaluated by regression fitting a line using the sum of least squares and assessing the Pearson correlation coefficient. This relationship was determined to be important because if test subjects had $\mathrm{SpO}_{2}$ levels that fell at different rates, there would be no apparent correlation between final $\mathrm{SpO}_{2}$ and experimental alarm time. However, if test subjects had a delay in the time at which $\mathrm{SpO}_{2}$ began to fall relative to $\mathrm{PiO}_{2}$ but at the same rate of fall, there would be a relationship evident. Several physiological mechanisms exist that could cause a delay in the time at which $\mathrm{SpO}_{2}$ begins to fall: one such mechanism is hyperventilation. A delay in start of the fall would still result in the same warning time for subjects because they would still have the same overall length of time at safe $\mathrm{SpO}_{2}$ levels, whereas a difference in rates of fall would mean shortened warning times for some subjects.

The data were normalized by a characteristic time, defined below. The characteristic time, which describes the time scale of a system ( $t^{*}$, seconds), was defined for this system as the total volume of gas in the breathing loop ( $\mathrm{V}_{\text {loop }}, \mathrm{SL}$ ) divided by the rate of oxygen consumption $\left(\mathrm{VO}_{2}, \mathrm{SL} / \mathrm{minute}\right)$, and is shown as Equation (3). Characteristic time is a concept commonly used to describe the rate at which a system responds to change.

$$
\text { (3) } t=60 * \frac{V_{\text {loop }}}{\mathrm{VO}_{2}}
$$

$\mathrm{V}_{\text {loop }}$ is the gas volume at a single atmosphere of pressure, so it is equal to the physical volume of the breathing loop, $\mathrm{V}_{\text {total, }}$ at one atmosphere. It should be noted that Equation (3) does not correct for variations in temperature between loops. A larger loop volume indicates more oxygen will be present in the breathing loop at the moment the $\mathrm{pO}_{2}$ falls below normal atmospheric levels, therefore larger loops or lower $\mathrm{VO}_{2}$ will provide longer warning times. The characteristic time allows for quantitative comparisons of how quickly a diver will breathe down a loop across different loop volumes and work rates. It also therefore allows for the data from the experiments described herein to be applied universally to estimate the warning time for any combination of loop volume and work rate. The warning times predicted by these tests were normalized by division by the characteristic time for each test subject. Characteristic time and the normalization process are addressed more fully in the Discussion section.

\section{RESULTS}

The numerical results and key values of all tests are shown in Tables 1 and 2. Two tests of the 20 total were excluded from the results because of failures of the mass spectrometer. Oxygen levels in the breathing loop and blood oxygen saturation levels for the tests performed at the surface are shown in Figure 2. The same values for the tests performed while at $77 \mathrm{fsw}$ depth are shown in Figure 3. Figures 2 and 3 visually show 

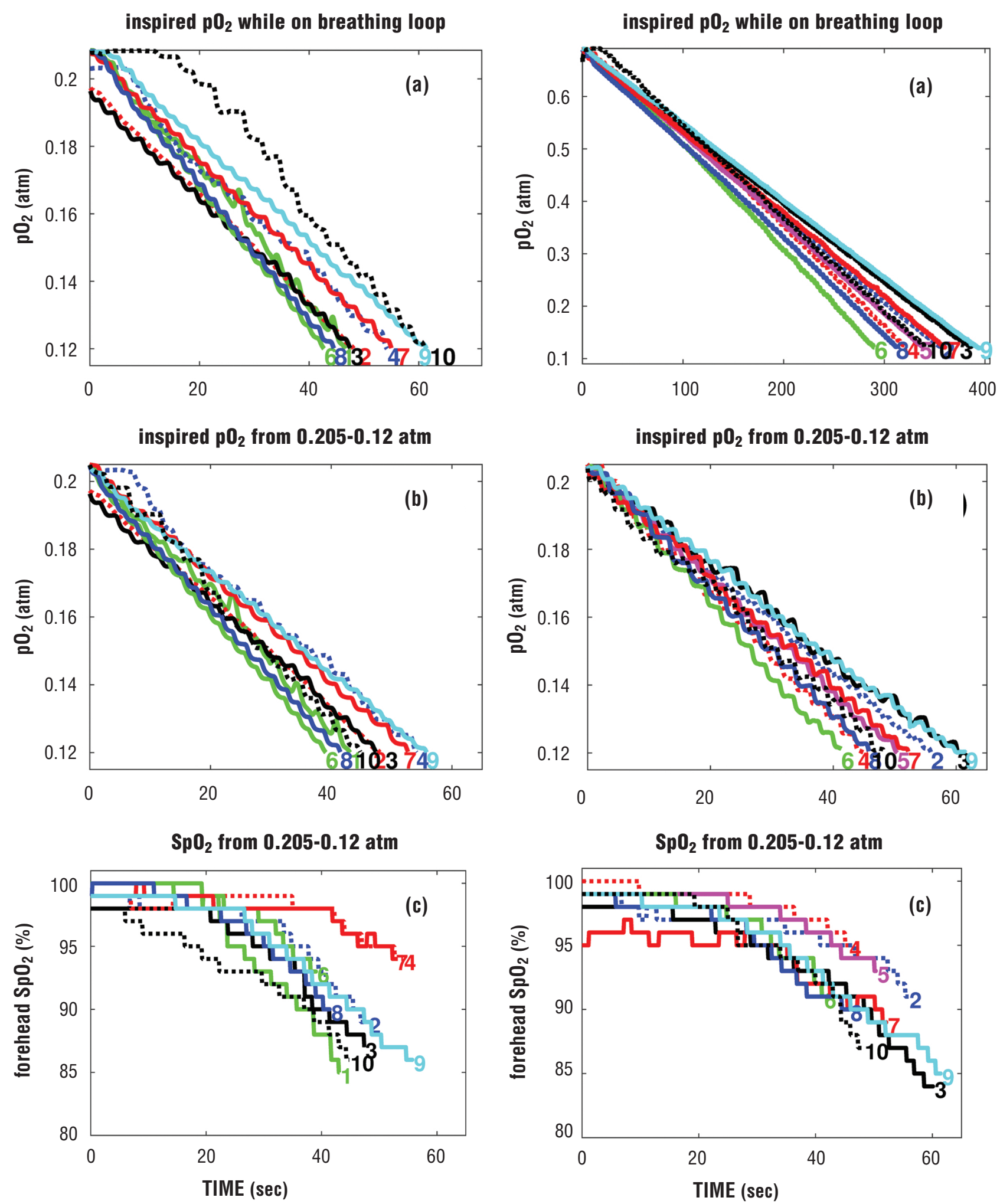

Figure 2: Individual results from the surface test. (a) inspired $\mathrm{pO}_{2}, \mathrm{t}=0$ when subject begins breathing the breathing loop; (b) inspired $\mathrm{pO}_{2}$, each test shifted so $\mathrm{t}=0$ occurs at $\mathrm{pO}_{2}=0.205$ (hypoxic time period); (c) blood oxygen saturation during the hypoxic time period, forehead oximeter.

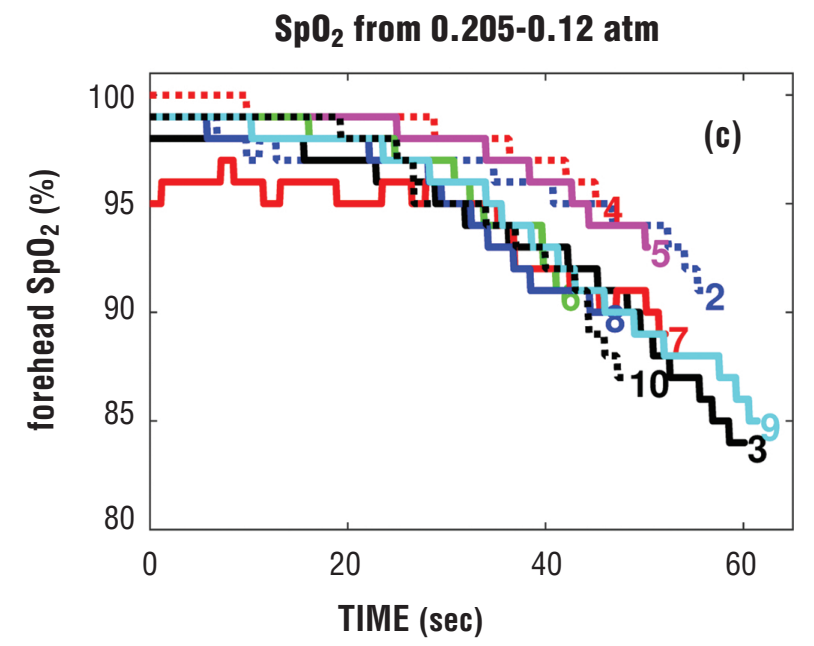

Figure 3: Individual results from the 77-fsw test.

(a) inspired $\mathrm{pO}_{2}, \mathrm{t}=0$ when subject begins breathing the breathing loop (b) inspired $\mathrm{pO}_{2}$, each test shifted so $\mathrm{t}=0$ occurs at $\mathrm{pO}_{2}=0.205$ (hypoxic time period) (c) blood oxygen saturation during the hypoxic time period, forehead oximeter. 
UHM 2017,VOL. 44, NO. 6 - PULSE OXIMETRY TO DETECT REBREATHER HYPOXIA

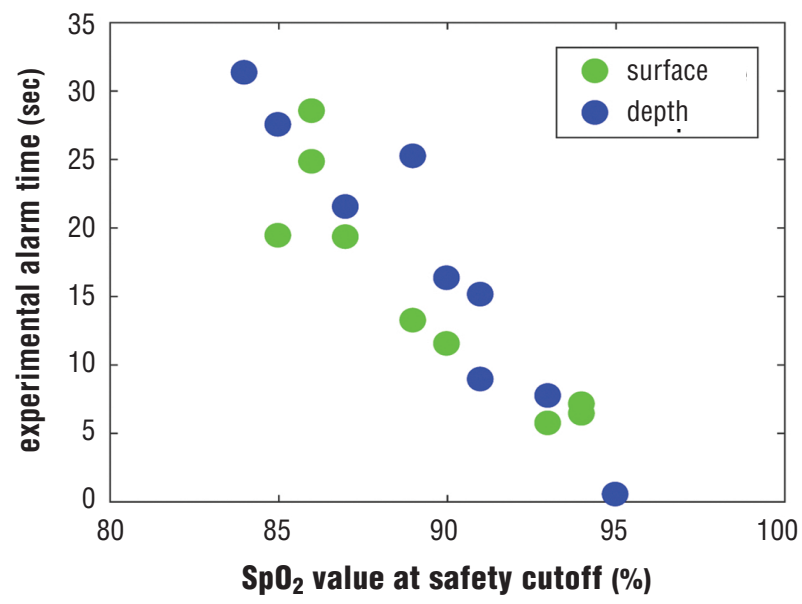

Figure 4: Experimental alarm time as a function of $\mathrm{SpO}_{2}$ value at the safety cutoff. Experimental alarm time is the time between $\mathrm{SpO}_{2}=95 \%$ and the safety cutoffs, always $\mathrm{PiO}_{2}=0.12$ atm in practice. A correlation is visually and statistically evident $(r=0.92)$.

the rate of decline of $\mathrm{PiO}_{2}$ and allow it to be correlated with the $\mathrm{SpO}^{2}$ reading over the course of the experiment. The test numbers from Tables 1 and 2 are used as labels to identify the individual curves in Figures 2 and 3. It should be noted that Figure 3c indicates that Test 7 started with an $\mathrm{SpO}_{2}=95 \%$; this is an anomalous reading that coincided with the final seconds before the hypoxic time period, as confirmed by comparison to the finger oximeter and has been considered the single "false positive" for an $\mathrm{SpO}_{2}=95 \%$ alarm level.

The $\mathrm{B}$ panels of Figures 2 and 3 show the data when time-shifted to have a consistent, $\mathrm{pO}_{2}$-based start point for each test. The use of a $\mathrm{pO}_{2}$-based start point prevented introduction of variability from experimental events such as the length of time it would take a test subject to accept and adjust the mouthpiece. The $\mathrm{SpO}_{2}$ values at the safety cutoff of $\mathrm{PiO}_{2}=0.12$ atm for each test are shown as Figure 4, plotted against the period of time between $\mathrm{SpO}_{2}=95 \%$ and the safety cutoff.

The ANOVA showed that the only statistically significant predictor of experimental alarm time was the $\mathrm{SpO}_{2}$ value at the time the safety cutoff was reached $(\mathrm{P}<0.0001)$. Depth showed no significant predictive value $(\mathrm{P}=0.46)$, and neither did rate of oxygen consumption $(\mathrm{P}=0.63)$. The lack of statistical relationship with oxygen consumption was likely because all test subjects had a targeted $\mathrm{VO}_{2}$ of $2 \mathrm{~L} /$ minute, and limited experimental deviation from this value occurred $(2.09 \pm 0.36 \mathrm{~L} /$ minute, mean $\pm \mathrm{SD})$. The regression fit between experimental alarm time and ending $\mathrm{SpO}_{2}$ has a strong linear correlation (Pearson correlation $\mathrm{r}=0.92$ ). The plots of $\mathrm{SpO}_{2}$ during the hypoxic window $\left(0.12<\mathrm{pO}_{2}<0.205 \mathrm{~atm}\right)$ for each test are shown as Figure 5, with their extrapolated fit lines drawn to $\mathrm{SpO}_{2}=80 \%$.

In addition to the values listed in Table 1 for a 95\% $\mathrm{SpO}_{2}$ alarm, warning times were also calculated assuming the oximeter alarm was set at a higher $\mathrm{SpO}_{2}$, between 96\%-98\%. Warning times were not calculated for the surface tests at a $98 \%$ alarm level because this saturation level can occur normally while at surfacelevel oxygen partial pressures. There was no statistically significant dependence of warning time on the saturation level at which the alarm is triggered between 95\%-97\% ( $\mathrm{p}=0.18$ ); however, this lack of significance is possibly because of the small number of data points.

\section{DISCUSSION}

While many rebreather designs attempt to build in redundancy to increase the safety of the system, every available design still has at least one single-point failure that can lead to hypoxia. Since it is unlikely that hypoxia will be detected by those who have not specifically experienced hypoxia training [6], these failures have led to casualties. Task-loaded working divers or divers experiencing nitrogen narcosis likely have an even lower chance of recognizing the symptoms on their own, and an even higher risk of failing to manually monitor their oxygen levels frequently enough. A pulse oximeter can provide a useful amount of warning time to all rebreather divers. A pulse oximeter could be positioned in one of several unobtrusive places on the body, including the forehead under the mask skirt, and would provide a reliable, convenient, completely redundant system of monitoring oxygen levels.

Tables 1 and 2 list the warning times for each test subject using 95\% $\mathrm{SpO}_{2}$ as the level at which an alarm would be initiated. This percentage was chosen because only one of the tests would have had a false positive at this level (Test 7, Figure 3c), and it provides a conservative minimum estimate for the utility of an oximeter at an oxygen consumption rate of $2 \mathrm{~L} /$ minute STPD. Additional warning time may be gained by setting the oximeter alarm threshold at a higher percentage; while this dataset did not achieve statistical significance for this trend, the lack of significance is possibly because of the small number of tests. However, this change would also incur an increase in the number of false alarms. 

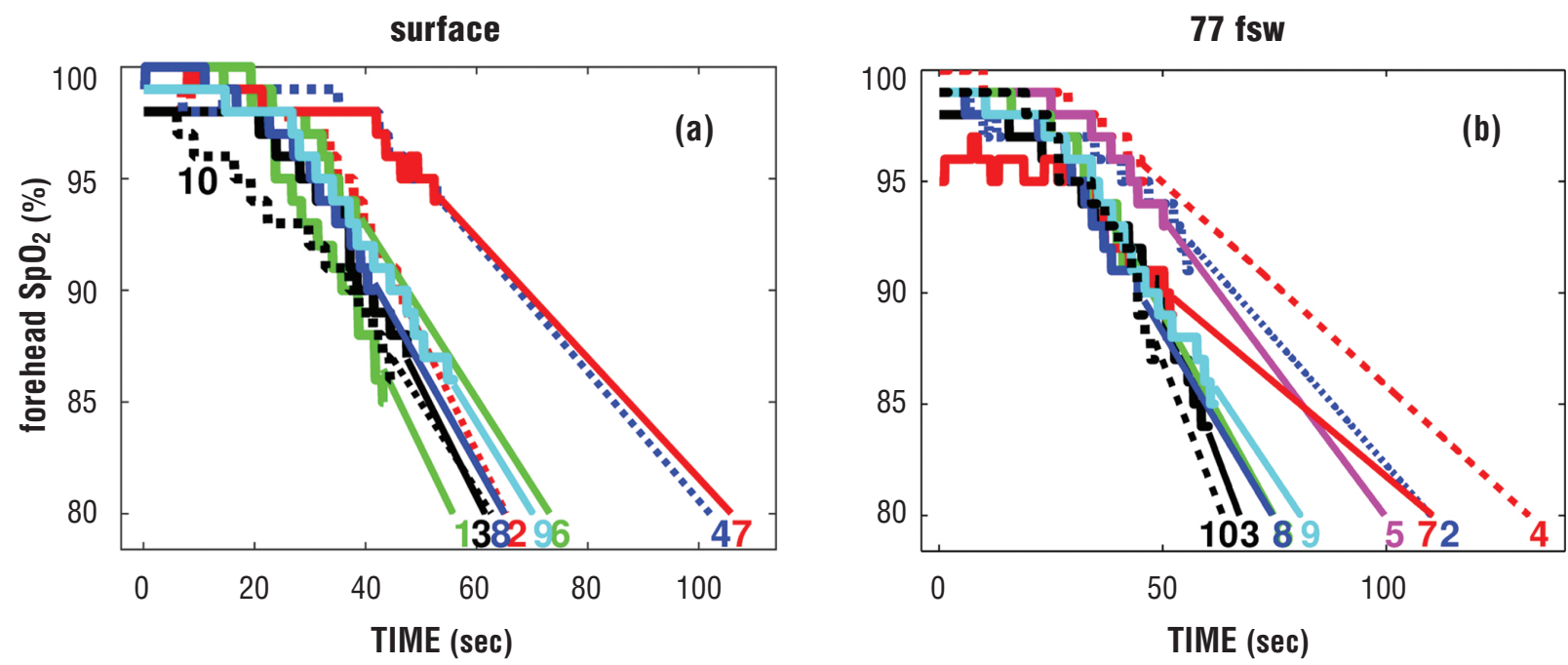

Figure 5: Sp02 data with extrapolated fit lines.

The $\mathrm{SpO}_{2}$ data are shown with the lines that were fit to the last 15 seconds of data before a safety cutoff was reached. These lines were then extended to find the projected time at which the subjects' $\mathrm{SpO}_{2}$ values would reach $80 \%$.

Figure 6 shows the mean minimum warning times for this test data for various alarm settings. The drawback to this increase in warning time would be an increase in false positive rate, potentially leading to diver refusal to use or acknowledge the alarm on working dives $[18,19]$.

Although at depth $\mathrm{PCO}_{2}$ may be higher and $\mathrm{PaO}_{2}$ lower for a given inspired $\mathrm{PO}_{2}$, there should be no difference in the rates of falling oxygen partial pressure and blood oxygen saturation at depth versus the surface. Nonetheless, the test at pressure was conducted to test the breathing loop under conditions more closely resembling actual use. Qualitative evaluation of these experimental trials indicates that the forehead oximeters can be susceptible to artifacts if the oximeter is not firmly affixed to the diver's forehead. Indeed, other research groups have performed extensive work attempting to correct for motion artifacts, concluding that stable positioning of the oximeter is key to measuring continuous, accurate saturation levels [20]. Should a pulse oximeter be converted into a rebreather-specific hypoxia detection device, the method of attachment to the forehead will be crucial and careful scientific evaluation of the final product will be necessary to determine the ideal set point required to minimize false positive rate while maximizing warning time.

Testing of oximetry levels in thermal studies has shown that a reduction in blood flow induced by ex- warning times at different alarm settings

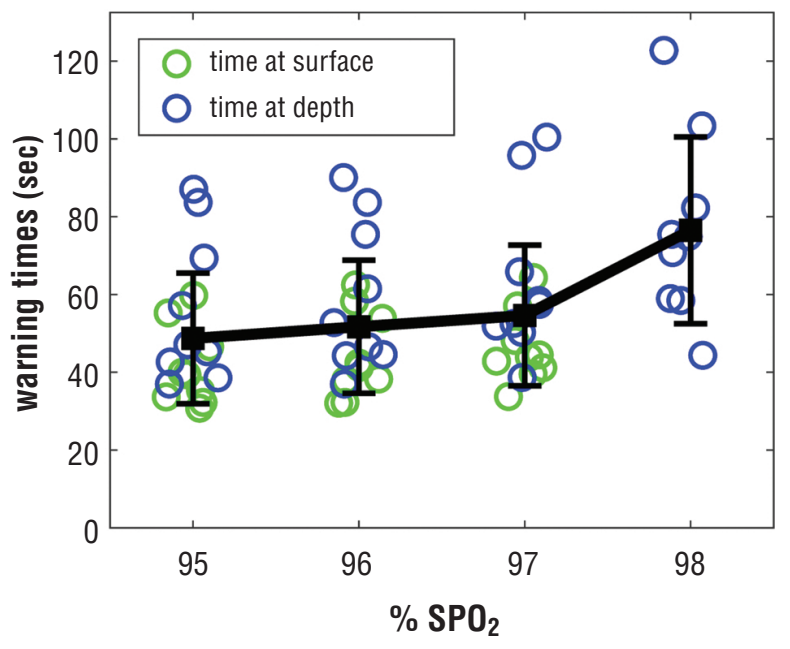

Figure 6: Warning times as a function of the blood oxygen saturation level used to activate the alarm.

The warning times were calculated using various Sp02 levels to indicate the level at which an alarm would trigger. Using a higher alarm level may increase warning time but also increases risk of false positives.

posure to cold causes a significant delay in detection of hypoxemia of up to four minutes in finger oximeters [10]. This delay prohibits the utility of a finger oximeter as a hypoxia detection device for any diver in cold water, as it is longer than the measured possible warning times. In these studies, conducted in the dry [9], the 
forehead probe was not susceptible to delayed hypoxia detection. Further investigation is needed to determine whether submersion in cold water has an effect.

For these tests warning times were defined using projected $\mathrm{SpO}_{2}$ values rather than the inspired $\mathrm{pO}_{2}$ level. An experimental cutoff hypoxia level of $\mathrm{pO}_{2}=0.12$ atm was used as a safety criterion. Existing literature (e.g., [14]) suggests that subjects can maintain consciousness indefinitely at this level, and indeed while some subjects reported increased perception of exertion toward the end of the hypoxic periods, no other adverse symptoms or loss of consciousness occurred during any of the tests. Aeromedical tests have indicated that average adults can maintain consciousness for a mean of two minutes at the much lower $\mathrm{pO}_{2}$ of $0.063 \mathrm{~atm}$ [14]. In 152 aircrew exposed acutely to an altitude of 25,000 feet (ambient $\mathrm{pO}_{2} 0.078 \mathrm{~atm}$ ) $\mathrm{SpO}_{2}$ was $58.4 \pm 0.9 \%$ and $64.5 \pm 1.2 \%$ (age groups $19-38$, 40-52 respectively, mean \pm SEM) at the time at which they developed clinically relevant symptoms or signs of hypoxia [21]. Therefore, even $\mathrm{SpO}_{2}=80 \%$ represents only the start of the period during which there is any risk of loss of consciousness, and provides a lower bound on the estimate of available warning time.

In our test subjects whose $\mathrm{SpO}_{2}$ levels indicated hyperventilation, the conservative $\mathrm{pO}_{2}$ cutoff of $0.12 \mathrm{~atm}$ provided an inaccurate estimate of the actual warning time before risk of loss of consciousness. In the face of low inspired $\mathrm{pO}_{2}$, arterial $\mathrm{HbO}_{2}$ saturation can be defended by hyperventilation (Eq. 2); therefore the hypoxic ventilatory response increased $\mathrm{SpO}_{2}$ relative to $\mathrm{pO}_{2}$. Because of this, a warning time calculated using $\mathrm{SpO}_{2}$ is a more robust indicator of any risk of loss of consciousness. For a given blood hemoglobin concentration, arterial oxygen status (arterial $\mathrm{SO}_{2}$ ) is the most robust measure of the level of oxygen actually available for physiological use. Brain $\mathrm{pO}_{2}$ can also be affected by changes in hemoglobin- $\mathrm{O}_{2}$ affinity and cerebral blood flow induced by hyperventilation-induced hypocapnia. This effect was demonstrated by showing that during hypoxemia (arterial $\mathrm{HbO}_{2}$ saturation $70 \%$ ) brain cytochrome a,a3 redox was higher during isocapnia $\left(\mathrm{PaCO}_{2}=38.5 \mathrm{mmHg}\right)$ vs. poikilocapnia $\left(\mathrm{PaCO}_{2}=27.3\right.$ $\mathrm{mmHg}$ ). However no one lost consciousness under either condition [22].

Variability in hypoxic ventilatory response, and hence in $\mathrm{pCO}_{2}$, will undoubtedly affect the $\mathrm{SpO}_{2}$ threshold for loss of consciousness; however, the range at which this occurs seems to be fairly narrow and has been determined to be less than $\mathrm{SpO}_{2}=70 \%$ (21).

Other reasons for inter-individual variability in rates of desaturation may include blood hemoglobin concentration. Indeed, a small effect of hemoglobin level on time of useful consciousness has been observed at altitudes of 35,000-37,500 feet [14]. However, those studies were performed at rest, where oxygen consumption is typically one-eighth that of the current study. Blood oxygen stores can be estimated using some reasonable assumptions. While exercising breathing air at sea level, arterial and venous blood volumes are approximately $30 \%$ and $70 \%$ of the total, respectively [23]. Assuming blood volume $=5 \mathrm{~L}, \mathrm{Hb}$ concentration $=$ $14 \mathrm{~g} / \mathrm{dL}, \mathrm{VO}_{2}=2 \mathrm{~L} /$ minute, arterial and mixed venous blood $\mathrm{O}_{2}$ saturations are $100 \%$ and $40 \%$ (typical measurements in humans exercising in the dry). Thus, blood $\mathrm{O}_{2}$ content is approximately $0.56 \mathrm{~L}$, almost equally divided between arterial and venous blood. This compares with a loop $\mathrm{O}_{2}$ volume of $2.3 \mathrm{~L}$ and lung $\mathrm{O}_{2}$ volume of $0.4 \mathrm{~L}$ (assuming functional residual capacity/FRC $3 \mathrm{~L}$ ). Blood $\mathrm{O}_{2}$ stores therefore comprise only $17 \%$ of the total $\mathrm{O}_{2}$ stores. An increase in $\mathrm{Hb}$ would increase the warning time slightly. Using the example above, raising blood $\mathrm{Hb}$ from 14 to $17 \mathrm{~g} / \mathrm{dL}$ would increase total $\mathrm{O}_{2}$ stores from 3.32 to $3.38 \mathrm{~L}$ (less than 2\%). If the diver breathes a $\mathrm{pO}_{2}$ higher than $0.21 \mathrm{~atm}$, loop $\mathrm{O}_{2}$ volume is correspondingly increased with very little change in blood $\mathrm{O}_{2}$ content. Thus the fraction of total $\mathrm{O}_{2}$ stores contained in the blood is further diminished, indicating that hemoglobin level plays only a minor part in determining warning time.

A similar argument applies to hemoglobin variants with differing affinity for oxygen, which are very rare. Arterial $\mathrm{O}_{2}$ content is determined by $\mathrm{Hb}$ concentration and arterial $\mathrm{pO}_{2}$, while venous $\mathrm{O}_{2}$ content is determined by arterial $\mathrm{O}_{2}$ content, $\mathrm{VO}_{2}$ and cardiac output. Thus, while arterial $\mathrm{O}_{2}$ content could conceivably be slightly reduced in the presence of a variant $\mathrm{Hb}$ (e.g., P50, one in which the oxygen tension at which hemoglobin is $50 \%$ saturated; this is significantly higher than normal, thus reducing arterial $\mathrm{O}_{2}$ saturation), the overall effect on blood $\mathrm{O}_{2}$ stores would be minimal. The presence of acidosis (which also affects hemoglobinoxygen binding) would also have minimal effect, as arterial $\mathrm{O}_{2}$ saturation is minimally affected by the 


\section{UHM 2017, VOL. 44, NO. 6 - PULSE OXIMETRY TO DETECT REBREATHER HYPOXIA}

degree of acidosis seen during exercise. The presence of $\mathrm{CO}$ in the blood would reduce blood $\mathrm{O}_{2}$ stores in proportion to the percentage of $\mathrm{HbCO}$, but would similarly have a minor effect, provided the diver does not have $\mathrm{CO}$ poisoning.

Although this study was not designed to measure the time to unconsciousness, the actual time would be longer than the warning time determined in this study. Using Equation 1, an estimate of the average time period between $\mathrm{pO}_{2}=0.12$ atm and 0.063 atm might be an additional 19 seconds, providing a total estimated 68 seconds of warning time with a $95 \% \mathrm{SpO}_{2}$ alarm $\left(\mathrm{V}_{\text {total }}=11 \mathrm{~L}, \mathrm{VO}_{2}=2 \mathrm{~L} /\right.$ minute $)$. However, it should be noted that the tests using a $\mathrm{pO}_{2}$ of 0.063 atm exposed the test subjects to hypoxia suddenly, rather than gradually, so the time of useful consciousness may vary under gradually lowering oxygen levels in this range.

These tests were performed using only one breathing loop configuration and one moderately high work rate $\left(\mathrm{VO}_{2}=2 \mathrm{~L} /\right.$ minute $)$ to test possible warning times experimentally for divers using Mk 16 rebreathers. However, there is an obvious advantage to converting these results into a universally applicable assessment of pulse oximeter utility across all work rates and rebreather designs. To accomplish this goal, the measured warning time for each test was divided by the $\mathrm{t}^{*}$ for that test, as was calculated using Equation (3) and provided in Tables 1 and 2. Loop volume alone is used for this calculation because the data did not indicate that the warning time was a function of either lung volume or functional residual capacity. It is possible that such a relationship may become apparent in future tests with more data. This division by $t^{*}$ helped reduce some of the variability induced by changes in individual oxygen consumption during the experiment, but more importantly it removed the warning time's dependence on loop volume and diver rate of oxygen consumption. However, it is important to note that some variation is still present because of biological variability between test subjects and normal experimental variations. When each warning time is divided by each respective test subject's t* value for that test, the mean value is $0.1556 \pm 0.0625$, a unitless number, for a $95 \%$ blood oxygen saturation alarm trigger. This value can then be multiplied by the $t^{*}$ for any other combination of loop volume and oxygen consumption. For example, if a person is diving a rebreather with a 9-L loop volume at an oxygen consumption rate of $1 \mathrm{~L} /$ minute (mild work), their predicted warning time is 84 seconds, calculated below as Equation (4).

$$
84.0 \text { seconds }=0.1556 * 60 \mathrm{smin} * \frac{9 \mathrm{~L}}{1 \mathrm{~L} / \mathrm{min}}
$$

Using this method, the results from these tests can be applied theoretically to any combination of loop volume and oxygen consumption. While it would be difficult for a diver to calculate their oxygen consumption in real time during a dive, it would be simple to calculate an estimated warning time beforehand using an approximated oxygen consumption consistent with the level of physical work required by their dive plan. However, it should again be emphasized that this was an exploratory study and therefore the results are based on a limited number of data points. These equations and values should be re-evaluated and computed in a final form based on the fully characterized performance and alarm levels of any device that is intended for field use as a hypoxia alarm. The calculations are presented herein primarily to provide a means of estimating oximeter utility for a variety of scenarios different from those tested.

Finally, there are practical issues that need investigation, including ease of use of pulse oximeter in the diving environment, durability of the probe-forehead adhesive and electrical reliability.

\section{CONCLUSIONS}

Given the preliminary nature of the investigation, the research herein tested subjects in a dry room rather than immersed in water for experimental simplicity. However, the physiological factors being examined behave similarly in both environments, namely hypoxia and $\mathrm{HbO}_{2}$ desaturation. The lack of water immersion may have influenced the test subjects' circulatory responses and the work of breathing in the rebreather breathing loop; however, these effects are estimated to be minor relative to the driving effect of the consumption of the oxygen in the loop. Therefore, a dry room was considered sufficient given the preliminary nature of the study. Future testing will include test subject immersion in water to incorporate these potential effects into the full device characterization. In addition, it should be re-emphasized that this study formed only a preliminary evaluation of the utility of such an oximeter-based safety device, and any manufactured 


\section{UHM 2017,VOL. 44, NO. 6 - PULSE OXIMETRY TO DETECT REBREATHER HYPOXIA}

unit should undergo further testing and analysis rather than using the results herein as the sole guidance for determining warning time.

Rebreather diving has one of the highest fatality rates of any recreational activity, and the military community is also not exempt from that danger. Hypoxia is by far the most common reason for death among the fatality cases with sufficient information [1]. We conclude that forehead pulse oximetry may be a practical safety measure that could warn divers of impending hypoxia and save lives.

\section{Acknowledgments}

We would like to gratefully acknowledge the Office of Naval Research (ONR) Undersea Medicine Program for

funding this work through Award Number N000141512519. We would also like to acknowledge the Department of Defense SMART Program, which fully funds the labor of Rachel Lance. The investigators are grateful to the invaluable staff at Duke Hyperbarics: Eric Schinazi, Albert Boso, Aaron Walker and Robert Brown, as well as the volunteers who served as experimental test subjects. This work was performed in memory of Dewey Smith, who experienced equipment failure leading to fatal hypoxia on a rebreather on May 5, 2009.

The authors declare that no conflicts of interest exist with this submission.

\section{REFERENCES}

1. Fock AW. Analysis of recreational closed-circuit rebreather deaths 1998-2010. Diving Hyperb Med. 2013; 43(2): 78-85.

2. Open Revolution accident review of life support systems: rebreather fatal accident database http://www.deeplife.co.uk/or_accident.php. Deep Life Ltd. [accessed December 22, 2016] .

3. Sieber A, Pyle R. A review of the use of closed-circuit rebreathers for scientific diving. Int J Soc Underwater Tech. 2010; 29(2): 73-78.

4. USN. U.S. Navy diving manual, rev. 6. 2011.

5. Silk R. Aquarius diver's death remains a question. Key West Citizen. May 9, 2009.

6. Island R, Fraley E. Analysis of USAF hypoxia incidents January 1976 through March 1990. 7th International Symposium on Aviation Physiology; Columbus, OH, USA. 1993. 664-668.

7. Wagner JL, Ruskin KJ. Pulse oximetry: basic principles and applications in aerospace medicine. Aviat Space Environ Med. 2007;78(10):973-8.

8. Stewart IB, Bulmer AC, Sharman JE, Ridgway L. Arterial oxygen desaturation kinetics during apnea. Med Sci Sports Exerc. 2005; 37(11): 1871-1876.

9. Thurk F, Gindlhumer 0, Kaniusas E. Reproducibility of cardiovascular and gas parameters in voluntary apnea related to apnea duration: a case study. In: IEEE, editor. 2014 IEEE International Symposium on Medical Measurements and Applications (MeMeA) 2014. 1-5.

10. MacLeod DB, Cortinez LI, Keifer JC, Cameron D, Wright DR, White WD, et al. The desaturation response time of finger pulse oximeters during mild hypothermia. Anaesthesia. 2005; 60: 65-71.

11. Torre-Bueno JR, Wagner PD, Saltzman HA, Gale GE, Moon RE. Diffusion limitation in normal humans during exercise at sea level and simulated altitude. J Appl Phys. 1985; 58(3): 989-995.

12. Wagner PD, Gale GE, Moon RE, Torre-Bueno JR, Stolp BW, Saltzman HA. Pulmonary gas exchange in humans exercising at sea level and simulated altitude. J Appl Phys. 1986; 61(1):260-270.
13. Fenn WO, Rahn H, Otis AB. A theoretical study of the composition of the alveolar air at altitude. Am J Physiol. 1946;146: 637-653.

14. Hall F. Interval of useful consciousness at various altitudes. J Appl Physiol. 1949;1(7):490-495.

15. Mackenzie CG, Riesen AH, Bailey JR, Tahmisian TN, Crocker PL. Duration of consciousness in anoxia at high altitudes. J Aviat Med. 1945; 16: 156-174.

16. Gale GE, Torre-Bueno JR, Moon RE, Saltzman HA, Wagner PD. Ventilation-perfusion inequality in normal humans during exercise at sea level and simulated altitude. J Appl Phys. 1985; 58(3): 978-988.

17. Kelman GR. Digital computer subroutine for the conversion of oxygen tension into saturation. J Appl Phys. 1985; 1966(21): 13751376.

18. Bustamante EA, Anderson BL, Bliss JP, editors. Effects of varying the threshold of alarm systems and task complexity on human performance and perceived workload. Human Factors and Ergonomics Society 48th Annual Meeting; 2004.

19. Bliss JP, Dunn MC. Behavioural implications of alarm mistrust as a function of task workload. Ergonomics. 2000; 43(9): 1283-1300.

20. Chon KH, Mendelson Y. Wearable wireless sensor for multi-scale physiological monitoring, ADA612520. MA: Worcester Polytechnic Inst; 2014.

21. Yoneda I, Tomoda M, Tokumaru O, Sato T, Watanabe Y. Time of useful consciousness determination in aircrew members with reference to prior altitude chamber experience and age. Aviat Space Environ Med. 2000; 71(1): 72-76.

22. Hampson NB, Camporesi EM, Stolp BW, Moon RE, et al. Cerebral oxygen availability by NIR spectroscopy during transient hypoxia in humans. J Appl Physiol. 1985; 1990(69): 907-913.

23. Wood JE. The veins: Normal and abnormal function. Boston, MA: Little Brown; 1965. 